\title{
Presencia catalana en la repoblación almeriense del siglo $\mathrm{XV}$ *
}

\author{
M. ${ }^{a}$ de los Desamparados Martínez San Pedro **
}

Almería se entrega por capitulación el día 10 de diciembre de 1489 , y en la Navidad de ese mismo año los Reyes Católicos entran en la ciudad tomando posesión de la misma. A través de una serie de pactos se establece que los musulmanes permanezcan en la ciudad con todas sus propiedades, a excepción de la Alcazaba, en la que se instala una fuerte guarnición cristiana, por el carácter costero y estratégico de Almería. Se mantendrán inalterables los aspectos jurídicos, religiosos y fiscales y tan sólo habrá un cambio esencial: la sustitución de las autoridades, ya que el gobierno pasará de manos musulmanas a manos cristianas, teniendo que someterse la población a la obediencia de los monarcas castellanos; pero las condiciones de la capitulación serán realmente suaves, hasta el extremo de permitir que los musulmanes conserven sus costumbres, sus prácticas religiosas, su indumentaria, etc.

No obstante, y a pesar de todas estas disposiciones benevolentes, en la primavera de 1490 los almerienses se unen a los habitantes de Guadix y de Baza e inician un levantamiento que pronto sería sofocado y reprimido por los Reyes Católicos.

La consecuencia inmediata fue un Decreto por el que los moros de Almería tendrán que abandonar la ciudad, por tratarse de un lugar fortificado, y únicamente se les permitirá residir en las alquerias y en los

* Comunicación presentada al I Congreso Internacional de Historia de los Pirineos. Cervera. Noviembre 1988.

** Colegio Universitario de Almería. 188.

1 M. Garrido AtienzA, Las capitulaciones para la entrega de Granada, 1910, págs. 185- 
lugares donde no existan fortalezas. Si esta decisión no les complacía, podían pasar a Africa, pero los que permanecieran en la zona quedaban completamente a merced de los vencedores y con muy pocas posibilidades de que prosperase una nueva rebelión ${ }^{2}$.

Esta expulsión provocará una situación nueva en Almería y su comarca, que inducirá a la Corona a plantearse la cuestión de la repoblación. El sistema a seguir era harto conocido y los Reyes, el 25 de mayo de 1491, dan poderes al repartidor Diego de Vargas para comenzar su misión ${ }^{3}$. De esta forma, se inicia en Almería lo que para el profesor Salvador de Moxó constituyó, sin duda, «uno de los fenómenos históricos más apasionantes — tal vez el más singular- de nuestra Edad Media, en cuanto supone la expresión tenaz, perseverante y laboriosa de la expansión cristiana hacia el sur, con plena consciencia para quienes la efectúan de que llevaban a cabo la ocupación permanente por una población estable de determinadas tierras para su cultivo, disfrute y establecimiento en ellas, lo que implicaba durante una larga etapa -dadas las circunstancias de la época - un apercibimiento para su defensa, a la vez que el esfuerzo inicial de roturación y ordenación agrícola primaria requería una incipiente colonización con medios limitados, lo cual se realizaba habitualmente dentro de una zona amenazada de ataques y depredaciones por parte de los musulmanes. Los peligros, sin embargo, no menguaron el entusiasmo y espíritu emprendedor de los repobladores, que hicieron de la colonización y cristianización de nuevos territorios una empresa popular" ${ }^{4}$.

En el caso que nos ocupa, la repoblación era ya uno de los últimos coletazos dentro de este proceso, pero no por ello menos interesante, pues nos vamos a encontrar con la presencia de personas procedentes de todos los puntos de la península.

Las normas generales que se deben cumplir, al efectuarse el Repartimiento de Allmería, fueron, como venía siendo habitual desde el siglo XIII, realmente atractivas.

${ }^{2}$ Sobre esta cuestión véase a Hernando del Pulgar, Crónica de los Reyes Católicos. Madrid 1953. Andrés Bernáldez, Memoria del Reinado de los Reyes Católicos. Madrid 1962. Gabriel Pascual y ORBaneJA. Historia de Almería, en su antigüedad, origen y grandeza. Almería 1975.

${ }^{3}$ C. Segura Graiño. El libro del Repartimiento de Almería. Madrid 1982, pág. 89.

${ }^{4}$ Salvador de Moxo. Repoblación y sociedad en la España cristiana medieval. Madrid 1979, pág. 10. 
Entre los vecinos que vengan a establecerse (se estipula que sean 500 ) debe haber escuderos, labradores, artilleros, mercaderes y oficiales. Posteriormente se añadirían "ombres de la mar". Han de estar casados o hacerlo en el plazo de tres meses. Las mujeres tienen que venir a residir con los maridos y, lo más importante, se conceden una serie de mercedes, privilegios y donaciones: tierras, parrales, huerta, olivos, frutales, norias, hornos, molinos, casa, tiendas para los oficiales, etc.; todo por unos servicios prestados y, sobre todo, a cambio de fidelidad y lealtad a los monarcas castellanos ${ }^{5}$.

Con ello se conseguirá, por una parte, repoblar Almería, que venía siendo desde siglos atrás, y por diversos motivos, muy castigada desde el punto de vista demográfico. Por otra, mantener las tierras cultivadas e intentar que la ciudad volviera a su antiguo esplendor comercial y maritimo. Por último, conseguir tener protegido y defendido un lugar tan importante y estratégico en el Mediterráneo, como lo era Almería.

\section{LA NUEVA POBlación ALMERIENSE: PRESENCIA CATALANA}

A finales del siglo xv, Almería empieza a cambiar su fisonomía anterior. La desolación de que nos habla Munzer ${ }^{6}$ comienza a transformarse en un ambiente más alegre y colorista, gracias a las gentes venidas de los más diversos lugares de la península.

La profesora Segura Graiño considera que Almería ofrece respecto al origen de la población una novedad con el resto de Andalucía, debido sin duda a su emplazamiento costero, ya que, si bien es verdad que llegan por mar un número considerable de mallorquines, no es menos cierto que los andaluces y murcianos son prácticamente inexistentes, tal vez porque Granada y Málaga fueran recogiendo y acogiendo a muchas personas que, aún con idea de venir a Almería, no llegaron nunca a su destino ${ }^{7}$.

${ }^{5}$ C. Segura Graiño. El libro del..., págs. 77-78.

6 Jerónimo MUNZER nos dice en sus Viajes de extranjeros por España y Portugal, que Almería tenía "mucha parte de la ciudad en ruinas y deshabitada...", pág. 348.

${ }^{7}$ C. Segura Graiño. La formación del pueblo andaluz. Madrid 1983, págs. 145-146. 
Delimitar exactamente el origen de la población es realmente difícil, ya que el Libro del Repartimiento apenas dice nada de la procedencia de los pobladores. Sin embargo, podemos entresacar muchos lugares, gracias a los apellidos toponímicos, muy abundantes y que indican el lugar inmediato de procedencia de los inmigrantes ${ }^{8}$. Este criterio, utilizado por muchos desde que el profesor D. Julio González defendiera la validez de este presupuesto, es el que he seguido para localizar algunos catalanes que aparecen en esta primera repoblación almeriense. Proceden de la provincia de Gerona y forman dos grupos bien diferenciados familiar y profesionalmente: uno, integrado por Juan Gironés, su hijo Miguel Gironés y su yerno Juan Vicente, son labradores. El otro, compuesto por el Maestre Blasco, carpintero, y su yerno Bartolomé Gironés, forman parte del grupo de los oficiales ${ }^{9}$.

Ahora bien, ¿a qué se debe esta presencia catalana, escasa por otra parte, en tierras del sur? Es difícil señalar los motivos. ¿Por qué se produce esta emigración de unas tierras tan lejanas, más ricas en principio y poco relacionadas con Almería? ¿Qué vinculación existió para que se produjera este trasvase de catalanes a tierras almerienses? Son tan pocos, en relación con el número total de repobladores, que el porcentaje es casi inapreciable. Pero lo cierto es que hay que contar con ellos.

Ya queda lejos la época en la que la acción de la marina catalana en aguas mediterráneas llega a su punto álgido; comienzan a surgir los primeros consulados y el comercio catalán ocupa un lugar preeminente ${ }^{10}$. Por otra parte, según Hillgarth, las bases para levantar un «imperio" catalán auténtico deben considerarse frágiles, aunque no se pueden negar los avances comerciales conseguidos en el Mediterráneo "1. Ahora bien, no podemos perder de vista que los catalanes que se desplazan a Almería no son mercaderes, sino labradores y artesanos. En este caso, ¿por que lo hicieron?

Yo me inclino a pensar que su venida se debe a otros factores. Cuando en los años 1229-1230 se produce la empresa reconquistadora

${ }^{8}$ M. GONZÁLEZ JIMÉNEZ, Inmigrantes y repoblación en la Andalucía del siglo xIII. Jaén, Jornadias de Historia Medieval Andaluza, 1984, pág. 89.

${ }^{9}$ Libro del Repartimiento de la ciudad de Almería. Archivo Municipal de Almería, fols. 147, 147v, 148, 187, 187v, 247 y $247 \mathrm{v}$. En adelante lo citaremos por LRA.

$10 \mathrm{~V}$. SALAVERT Y ROCA. La expansión catalano-aragonesa en el siglo xIV. Madrid, Actas del I Simposio de Historia Medieval, 1973, pág. 27.

$" \mathrm{~J}$. N. Hillgarth. El problema del imperio catalano-aragonés. Barcelona-Roma, Actas del I Congreso Internacional de Historia Mediterránea, 1980, págs. 158-159. 
de Mallorca, parece indudable que la isla, de la que se habían retirado muchos musulmanes, va a ser repoblada prácticamente en su totalidad por catalanes ${ }^{12}$. Sabemos que de Gerona acuden gentes y que, aunque se les concede libre circulación con sus mercancias, hay muchos que prefieren instalarse en las alquerías y zonas rurales para dedicarse a la agricultura. ¿No serán los catalanes - a los que estamos dedicando este estudio- sucesores de aquéllos? Hay que tener en cuenta que Mallorca, a lo largo del siglo XV, va a pasar por una fase muy crítica como resaca de los acontecimientos turbulentos del siglo xIV: crisis económica, rivalidades internas, secuelas de infortunios naturales (pestes, sequias, inundaciones en 1403), gestiones administrativas desacertadas, etc., de forma que el ambiente colectivo era de franco pesimismo, escepticismo e insatisfacción ${ }^{13}$.

Todas estas razones alentaron, sin duda, a las clases menos acomodadas a buscar un mayor bienestar; de tal forma, que la proximidad geográfica, unas condiciones climáticas muy parecidas y, sobre todo, las magníficas condiciones económicas presentadas en las normas generales del Repartimiento pudieron muy bien ser el factor decisivo para que nuestros protagonistas, mezclados con 19 vecinos mallorquines ${ }^{14}$, se trasladaran a tierras almerienses, buscando un lugar definitivo de asentamiento y unas mejores condiciones de vida. No hay que olvidar que nadie arriesga su seguridad ni abandona su tierra por algo desconocido, cuando no existen ciertas esperanzas de mejora social y fundadas promesas de beneficios inmediatos, todo ello bajo el denominador común de algo tan importante como puede ser la libertad ${ }^{15}$.

Nos encontramos, pues, con dos familias claramente diferenciadas, con actividades distintas cada una: la agricultura y la artesanía. ¿Por qué podemos aventurar esta afirmación, si el Libro del Repartimiento no especifica la profesión, haciéndolo tan sólo del Maestre Blasco, del que insinúa que es carpintero? ${ }^{16}$. Simplemente por los bienes que reciben cada uno de los pobladores.

${ }^{12}$ S. Moxo, Repoblación y sociedad..., págs. 328-329.

13 Álvaro, Santamaria Arandez, Mallorca en el siglo xiv, Madrid, Actas del I Simposio de Historia Medieval, 1973, pág. 225.

${ }^{14}$ C. Segura Graino, Bases socioeconómicas de la población de Almería (Siglo xv), Madrid 1979, págs. 77 y 80 .

${ }_{15}$ M. GonZALEZ, Inmigrantes y repoblación..., pág. 93.

${ }^{16}$ LRA, fol. 187. 
Cuando en las normas generales se establece cómo se han de hacer los lotes y repartir los bienes, se dice claramente que entrarán 200 labradores que recibirán 30 pies de olivo cada uno, 50 tahullas ${ }^{17}$ de huerta entre todos, una tahulla de parral y 8 de tierra, casa en el campo con frutales y casa en la ciudad.

Para los oficiales, que serán 100 , las normas no están tan claras, puesto que no se dan cantidades fijas, ya que se destinan 100 pies de olivos, 100 tahullas de huerta en las afueras de la ciudad y en el Alquián, 100 tahullas de tierra y 40 tahullas de parral a repartir entre todos los oficiales de todos los oficios, pero de forma desigual, considerando sus méritos o su prestigio ${ }^{18}$. Lo que sí se deja bien establecido es que «a estos ofiçiales les an de dar las tiendas francas que son del Rey e de la Reina" ${ }^{19}$.

\begin{tabular}{|l|c|c|c|c|}
\cline { 2 - 5 } \multicolumn{1}{c|}{} & $\begin{array}{c}\text { Olivos } \\
\text { (pies) }\end{array}$ & $\begin{array}{c}\text { Huerta } \\
\text { (tahullas) }\end{array}$ & $\begin{array}{c}\text { Parral } \\
\text { (tahullas) }\end{array}$ & $\begin{array}{c}\text { Tierra } \\
\text { (tahullas) }\end{array}$ \\
\hline Labradores (200) & 30 & $\begin{array}{c}50 \\
\text { entre todos } \\
100\end{array}$ & 1 & 8 \\
Oficiales (100) & $\begin{array}{c}100 \\
\text { entre todos }\end{array}$ & $\begin{array}{c}40 \\
\text { entre todos }\end{array}$ & $\begin{array}{c}100 \\
\text { entre todos }\end{array}$ \\
\hline
\end{tabular}

No siempre se respetaron las normas. En algunos casos se mejoraron las suertes y en otros no se entregó lo convenido, pero se compensó la falta de unas tierras de cultivo con mayor cantidad de otras, apareciendo en el registro todas las advertencias sobre estas sustituciones (Cuadro núm. 3).

Según esto, está claro que los catalanes que vienen a residir a Almería pertenecen a estos grupos, siendo los oficiales claramente beneficiados, sobre todo el Maestre Blasco que, por su edad, valía, responsabilidad o eficacia, parece que estuvo muy bien considerado (Cuadros núms. 3 y 4).

${ }^{17}$ La tahuila, medida empleada en la zona levantina, equivale a 11 áreas y 18 centiáreas, o sea $1.118 \mathrm{~m}^{2}$.

${ }_{18}^{18}$ LRA, fol. $3 \mathrm{v}$ al $5 \mathrm{~V}$.

19 LRA, fol. 3v. 


\section{BIENES RÚSTICOS}

Las suertes de la familia de Juan Gironés, todos ellos labradores, son muy similares. Todos reciben junto al río, en Mondújar, o en tierras pertenecientes a la zona de Alquián sus correspondientes lotes de tierra, huerta, parral, olivos y árboles frutales (Cuadros núms. 3 y 4). Es curioso advertir que la casa que se les asigna en el campo, concretamente en Mondújar, será compartida por padre, hijo y yerno.

El caso de los oficiales es distinto por dos razones:

1. El Libro del Repartimiento, como ya se ha dicho, no establece norma fija en el reparto de las suertes.

2. La categoría de los dos oficiales, a los que nos referimos, debió ser muy diferente a juzgar por los lotes que recibe cada uno.

Se desprende que el Maestre Blasco, carpintero, tuvo en la ciudad un peso específico, superior con mucho, al de Bartolomé Gironés, del que desconocemos su oficio, pero creemos que por razón de parentesco pudo ser también la carpintería, y que de alguna manera dependía de su suegro.

El Maestre Blasco recibe un lote muy amplio, para tratarse de un oficial, en la zona de Viator, viéndose favorecido con casa y noria ${ }^{20}$.

La suerte de Bartolomé Gironés es sensiblemente menor y además muy dispersa, pues recibe pequeñas parcelas en Mondújar, Huercal y El Alquián ${ }^{21}$. La diferencia es evidente.

\section{BIENES URBANOS}

La nueva organización urbana se llevó a cabo dividiendo la ciudad en cuatro partes, collaciones o parroquias ${ }^{22}$. Aunque esta división tendrá

20 LRA, fol. 187.

${ }^{21}$ LRA, fol. 247.

${ }^{22} \mathrm{M}^{\text {a }}$ de los Desamparados Martinez San Pedro, La ciudad de Almeria a finales del siglo xv: Notas sobre su población y urbanismo, Almeria, Homenaje al Padre Tapia, 1988. págs. 193-196. 
efectos religiosos muy posteriormente, a excepción de la Iglesia Mayor o Parroquia de Santa María, en el aspecto administraiivo comienza a funcionar desde el primer momento. Las collaciones recibieron los nombres de Santa María, ya citada, San Pedro, Santiago y San Juan.

Los catalanes, igual que ocurre en el campo, reciben las casas agrupadas en dos bloques. Por un lado nos encontramos a la familia de los labradores que, aunque en dos collaciones distintas, Santiago y San Pedro, vivieron muy cercanos e incluso Juan Gironés y Juan Vicente fueron vecinos y sus casas colindanies.

El Maestre Blasco recibe su casa en la collación de San Pedro y, por último, Bartolomé Gironés, que a mi juicio fue el menos afortunado del conjunto tuvo que vivir en una zona perteneciente a la collación de San Juan, en unas casas muy limítrofes de la ciudad, que habian sido moreria y se habían recuperado para los nuevos vecinos cristianos (Cuadro núm. 5).

La convivencia de los catalanes con el resto de la población, así como su integración social, tuvo que ser buena. Se vieron obligados por razón de vecindad y de profesión, tanto en el campo como en la ciudad, a convivir con distintos grupos sociales, muy diferentes entre sí, que procedian de lugares muy diversos y alejados, y cuyas costumbres y formas de vida serían, sin lugar a dudas, totalmente distintas (Cuadros núms. 2 y 5).

Pero lo cierto es que la población de Almería, tras esta primera penetración demográfica cristiana, tan heterogénea por otra parte, ya que no hay que olvidar la presencia de algunos musulmanes fieles a la Corona, se va reordenando definitivamente. $Y$ sin lugar a dudas, la elevada conciencia que los nuevos pobladores tienen de su misión colonizadora, hará que se vaya compensando la escasez de efectivos humanos y el pariorama, tanto agrario como urbano, vaya transformándose positivamente.

Pues bien, a esta transformación, aunque de modo muy limitado, por su escaso número, también contribuyeron algunas familias catalanas. 


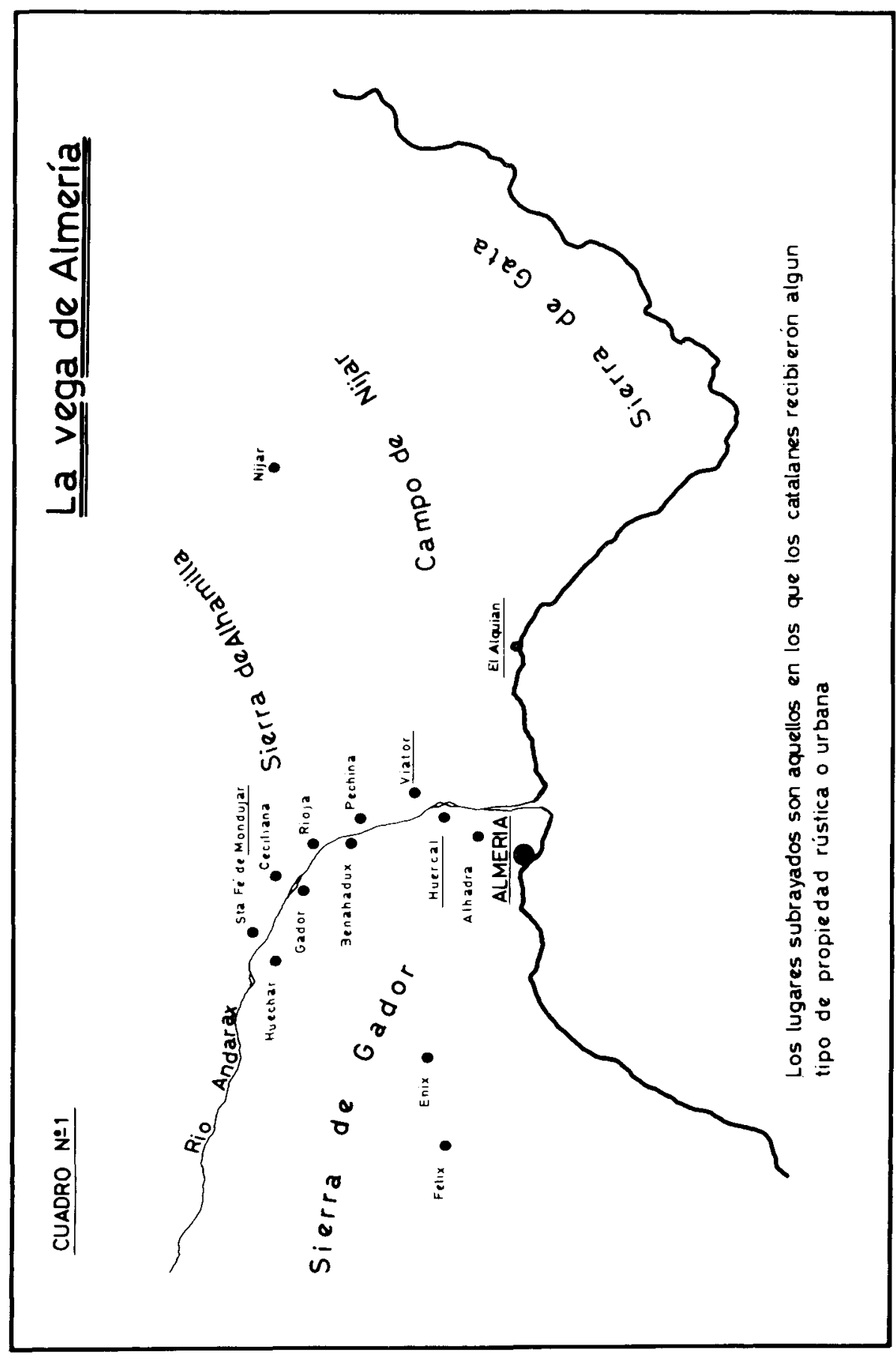




\section{CUADRO NÚM. 2}

\section{Ubicación de los bienes rústicos de los catalanes y sus vecinos} colindantes

\begin{tabular}{|c|c|c|}
\hline REPOBLADOR & UBICACION & VECINOS \\
\hline JUAN GIRONÉS & $\begin{array}{l}\text { Mondújar } \\
\text { El Alquián }\end{array}$ & $\begin{array}{l}\text { Chacón } \\
\text { Juan Vincente } \\
\text { Miguel Gironés } \\
\text { Bartolomé Reverte } \\
\text { Diego de Salamanca } \\
\text { Juan Guillén } \\
\text { Pero Oliver } \\
\text { Juan de la Hoz } \\
\text { Marina Narbáez } \\
\text { Juan Terín } \\
\text { Jordano }\end{array}$ \\
\hline $\begin{array}{l}\text { MIGUEL GIRONÉS } \\
\text { Hijo de Juan Gironés }\end{array}$ & $\begin{array}{l}\text { Mondújar } \\
\text { El Alquián }\end{array}$ & $\begin{array}{l}\text { Bartolomé Silva } \\
\text { Juan Vicente } \\
\text { Juan Gironés } \\
\text { Juan de Gorrús } \\
\text { Nuflo de Soler } \\
\text { Pero Oliver } \\
\text { Juan de la Hoz } \\
\text { Marina Narbáez } \\
\text { Bartolomé Gironés } \\
\text { Ruiz de Deça } \\
\text { Fuerrunia } \\
\text { Francisco de Grado } \\
\text { Chacón } \\
\text { Juan Guillén }\end{array}$ \\
\hline $\begin{array}{l}\text { JUAN VICENTE } \\
\text { Yerno de Juan Gironés }\end{array}$ & $\begin{array}{l}\text { Mondújar } \\
\text { EI Alquián }\end{array}$ & $\begin{array}{l}\text { Miguel Gironés } \\
\text { Juan Gironés } \\
\text { Bartolomé Silva } \\
\text { Bartolomé Cañete } \\
\text { Pero Verdú } \\
\text { Peruchón } \\
\text { Juan Compani } \\
\text { Ruiz de Deça } \\
\text { Fuerrunia } \\
\text { Francisco de Grado } \\
\text { Martín de Cafra } \\
\text { Bartolomé Reverte } \\
\text { Lorenço }\end{array}$ \\
\hline $\begin{array}{l}\text { BARTOLOMÉ GIRONÉS } \\
\text { Yerno del Mestre Blasco }\end{array}$ & $\begin{array}{l}\text { Mondújar } \\
\text { El Alquián } \\
\text { Huercal }\end{array}$ & $\begin{array}{l}\text { Juan León } \\
\text { Miguel Gironés } \\
\text { Diego Navarro } \\
\text { Juan Gallarte } \\
\text { Hernán Cano }\end{array}$ \\
\hline MAESTRE BLASCO & Viator & $\begin{array}{l}\text { Guillén de Mira } \\
\text { Gil de Requena }\end{array}$ \\
\hline
\end{tabular}




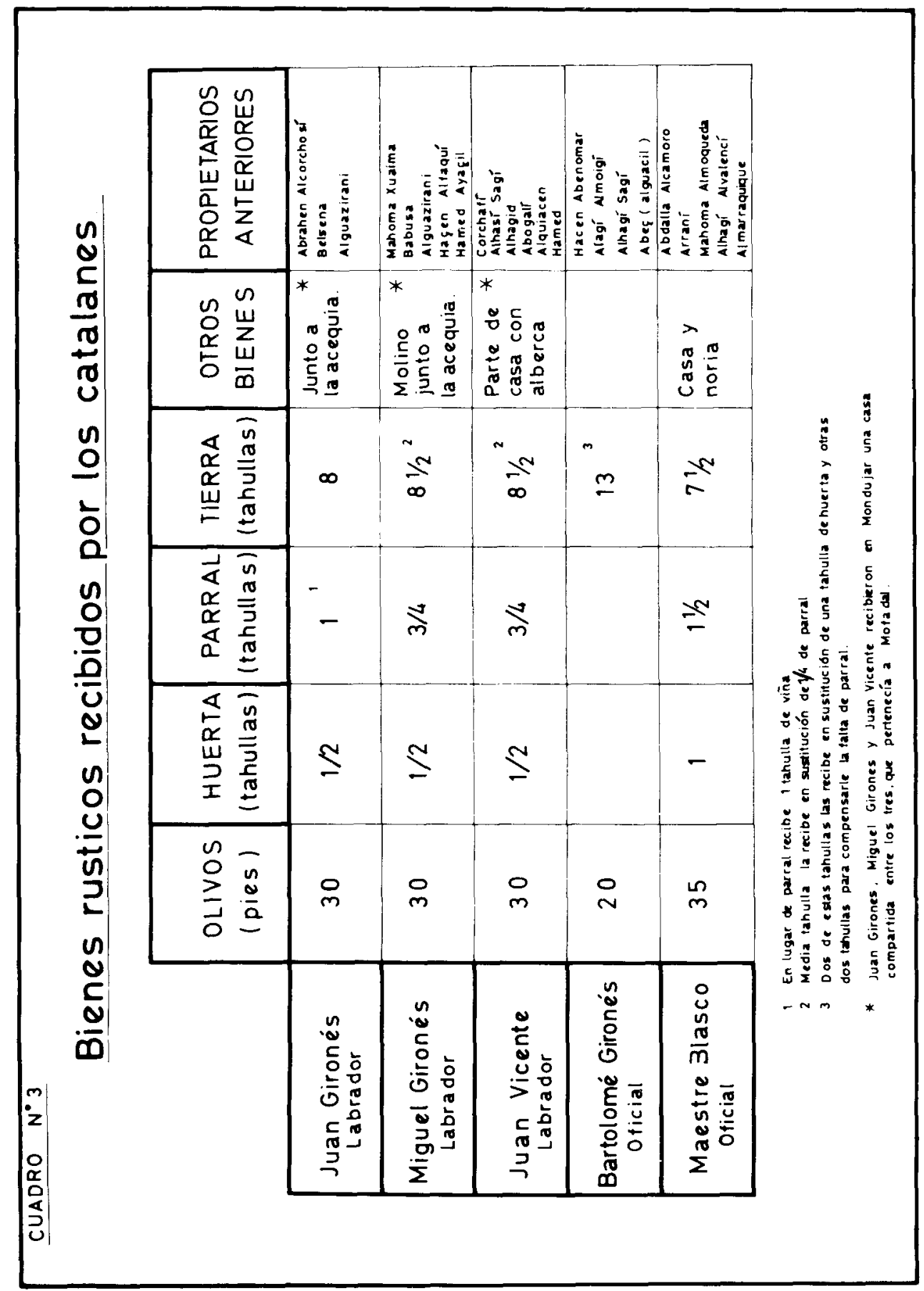




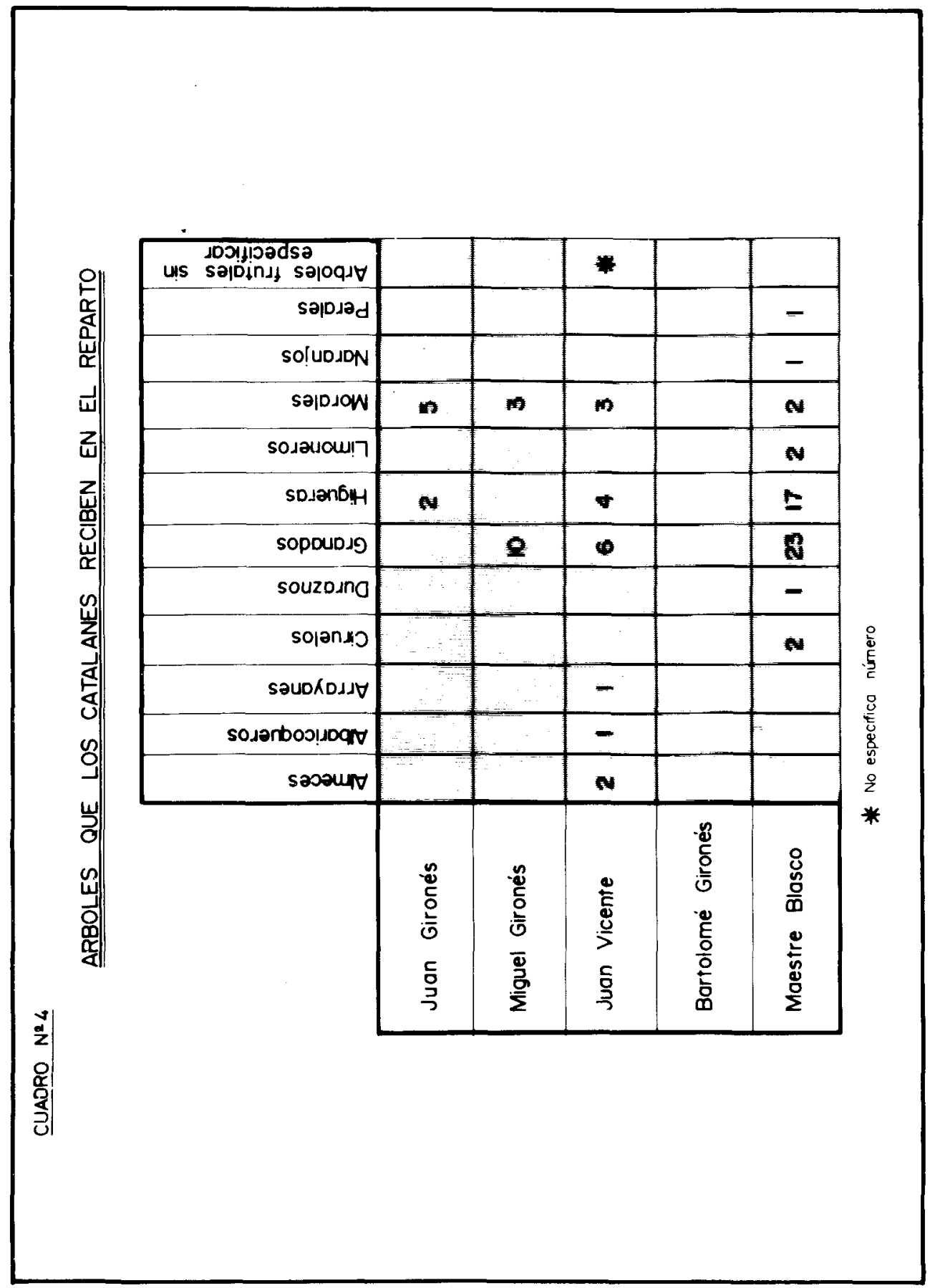


Presencia catalana en la repoblación almeriense del siglo XV

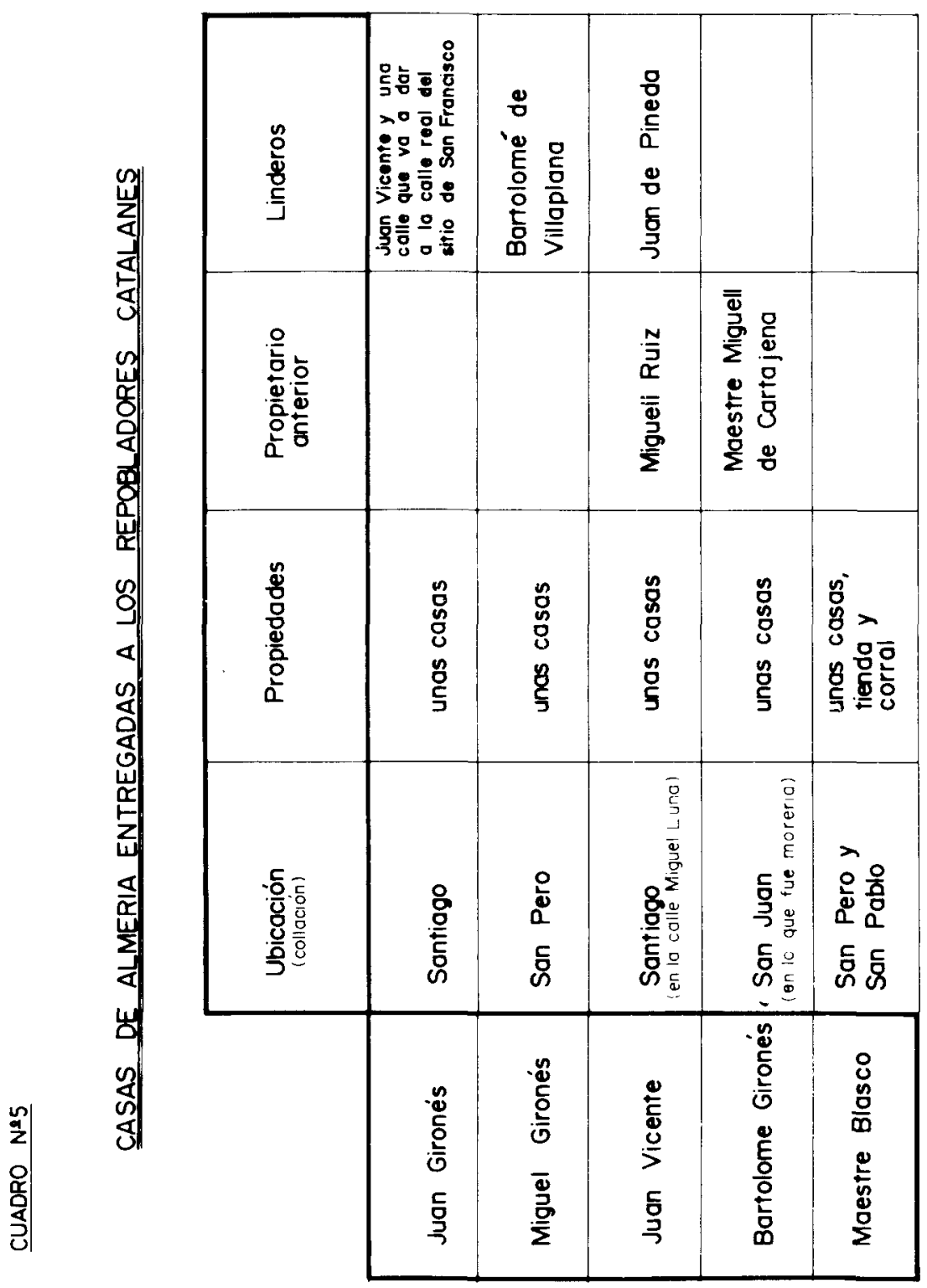

